\title{
Screen-detected colorectal cancers are associated with an improved outcome compared with stage-matched interval cancers
}

\author{
M D Gill ${ }^{\star 1,2,3}$, M G Bramble 2,3 M A Hull ${ }^{4}$, S J Mills ${ }^{1,3}$, E Morris $^{4}$, D M Bradburn ${ }^{1,3}$, Y Bury ${ }^{5}$, C E Parker $^{3,6}$, \\ T J W Lee Len $^{3,7}$ and $\mathrm{J}$ Rees $2,3,6$ \\ ${ }^{1}$ Northern Colorectal Cancer Audit Group, North East England, UK; ${ }^{2}$ School of Medicine, Pharmacy and Health, University of \\ Durham, Durham, UK; ${ }^{3}$ Northern Region Endoscopy Group, North East England, UK; ${ }^{4}$ Leeds Institute of Cancer and Pathology, \\ University of Leeds, Leeds, UK; ${ }^{5}$ Royal Victoria Infirmary, Newcastle, UK; ${ }^{6}$ South Tyneside Foundation Trust, South Tyneside, UK \\ and ${ }^{7}$ North Tyneside General Hospital, Northumbria Healthcare NHS Foundation Trust, Northumberland, UK
}

Background: Colorectal cancers (CRCs) detected through the NHS Bowel Cancer Screening Programme (BCSP) have been shown to have a more favourable outcome compared to non-screen-detected cancers. The aim was to identify whether this was solely due to the earlier stage shift of these cancers, or whether other factors were involved.

Methods: A combination of a regional CRC registry (Northern Colorectal Cancer Audit Group) and the BCSP database were used to identify screen-detected and interval cancers (diagnosed after a negative faecal occult blood test, before the next screening round), diagnosed between April 2007 and March 2010, within the North East of England. For each Dukes' stage, patient demographics, tumour characteristics, and survival rates were compared between these two groups.

Results: Overall, 322 screen-detected cancers were compared against 192 interval cancers. Screen-detected Dukes' C and D CRCs had a superior survival rate compared with interval cancers $(P=0.014$ and $P=0.04$, respectively). Cox proportional hazards regression showed that Dukes' stage, tumour location, and diagnostic group (HR 0.45, 95\% Cl 0.29-0.69, $P<0.001$ for screendetected CRCs) were all found to have a significant impact on the survival of patients.

Conclusions: The improved survival of screen-detected over interval cancers for stages $C$ and $D$ suggest that there may be a biological difference in the cancers in each group. Although lead-time bias may have a role, this may be related to a tumour's propensity to bleed and therefore may reflect detection through current screening tests.

Colorectal cancer (CRC) is a major public health problem. Men have a 1 in 16 and women have a 1 in 20 lifetime risk of being diagnosed with CRC. In 2007-2008, there were 17 100 new cases diagnosed in men and 14400 in women, making it the third most commonly diagnosed cancer (excluding non-melanoma skin cancers) in the United Kingdom (UK). In the same year, $\sim 13300$ people died from CRC, the second highest cause of cancer mortality in the UK (Cancer Research UK, 2010).

The NHS Bowel Cancer Screening Programme (BCSP) was introduced in April 2006 in order to decrease population mortality from CRC. The primary aim of the programme is to detect CRC at an earlier stage, thereby improving survival (NHS Cancer 
Screening Programmes, 2006). A secondary aim is to identify and remove colorectal adenomas.

In the North East of England, full uptake of the screening programme was achieved by April 2008. The population eligible for screening included anyone aged 60-69 years, extended to 74 years in January 2010. Screening comprises biennial nonrehydrated guaiac-based faecal occult blood tests (FOBt; HemaScreen, Immunostics Inc.). For those with positive results, a colonoscopy is offered (NHS Cancer Screening Programmes, 2006). Those with a negative FOBt are re-invited to undergo FOB testing in 2 years' time.

We have previously reported a comparison of screen-detected and interval CRCs diagnosed after a positive or negative BCSP FOB testing, respectively (Gill et al, 2012). Interval CRCs (defined as a cancer diagnosed after a negative screening episode, before the next planned screening test) have been shown by this and other studies to be more commonly found in women and to be located in the right colon (Steele et al, 2011; Morris et al, 2012a). As nearly 40\% of screen-detected cancers are Dukes' Stage A, it has been presumed that it is the early tumour stage which influences the survival rate compared with the interval cancer group. It is not known whether interval cancers are de novo lesions following a true negative screening test, or represent a false negative test or further investigation of a 'missed' lesion (Cooper et al, 2012). Interval CRCs are more frequently found in the right colon, and are often sessile, making them harder to detect at colonoscopy (Harvey and Ruszkiewicz, 2007). However, interval CRCs are more likely than screen-detected CRCs to have features of microsatellite instability (MSI), as a marker of genetic instability. Lesions with MSI are associated with rapid growth, and therefore may develop between examinations. To date, studies investigating the biology of interval cancers have been based on those detected in symptomatic populations (Sawhney et al, 2006; Arain et al, 2010; Shaukat et al, 2010).

The aim of this study was to analyse survival after diagnosis of individuals with a screen-detected CRC compared with individuals with an interval CRC when matched for tumour stage.

\section{MATERIALS AND METHODS}

The Northern Region Colorectal Cancer Audit Group (NORCCAG) registry was interrogated to identify all patients diagnosed with a CRC between 1 April 2007 and 31 March 2010, in the screening age range of 60-69 years. These patients were crossreferenced with the regional bowel cancer screening database to obtain each patient's screening history. Patients were then categorised into their diagnostic category of either screen-detected or interval CRCs.

The study was classed as a service evaluation, therefore formal ethical approval was not required. The National Information Governance Board (NIGB) accepted that pseudo-anonymisation of patients between databases was sufficient for no formal approval to be required.

American Society of Anaesthesiologists (ASA) physical status grade was used as a surrogate for severity of patient's comorbidity, being dichotomised into grades 1-2 or 3-5 (data recorded in the NORCCAG database, and supplemented where possible from patient records). Tumour location was dichotomised as distal to the splenic flexure or proximal (up to and including the splenic flexure). Deprivation level was calculated using the participants' postcode to derive their respective index of multiple deprivation rank (2007) for the Lower Super Output Area that they reside in. Patients were then grouped into their respective quintiles, from most affluent to most deprived. The modified Dukes' staging classification (stages A-D) was used to stage each tumour. Local excisions included all endoscopic polypectomies and trans-anal resection of tumours. Management of all CRC cases were discussed in dedicated colorectal multidisciplinary team meetings. No a priori statistical analysis was performed, it was solely on the population within the defined database. Pearson's chi-squared tests were used for variables of gender, deprivation, ASA grade, tumour location and Dukes' stage. The log-rank Mantel-Cox test used for survival analysis, and Cox proportional hazards regression for multivariate analysis. Survival length was calculated from date of diagnosis to death, or censored at the end of available follow-up (1 March 2012). Data were analysed using SPSS version 19.0 (SPSS Inc., Chicago, IL, USA). Significance was assumed at the 0.05 level.

\section{RESULTS}

Of 514 CRCs detected within the study period, 322 (67.6\%) were screen-detected and 192 (37.4\%) were interval CRCs. All interval cancers were diagnosed after an overall normal FOBt, with 15 (7.8\%) interval cancers submitting one unclear FOB test first, before having two normal tests. There were no post-colonoscopy interval cancers. Mean survival length was 32.1 months (s.e.m. 0.59 months). Results are presented by modified Dukes' stage, and are shown in Table 1.

Outcomes for Dukes' A cancers. One of 36 (2.8\%) of Dukes' A interval cancers and 15 of 125 (12.0\%) of screen-detected cancers were diagnosed after the incident (second round) of FOB tests. There were no significant differences found in tumour site, $\mathrm{T}$ stage, patient comorbidity level, or deprivation level between interval and screen-detected Dukes' A cancers. Despite comparable T staging, there were significantly more screen-detected CRCs managed with local excision compared with interval CRCs (30.4\% vs $11.1 \%$ ). Despite this, the 30-day mortality rate and overall survival rate (on Kaplan-Meier analysis) were equivalent between screen-detected and interval Dukes' A CRCs (log-rank Mantel-Cox $\chi^{2}=2.901$, $\mathrm{df}=1, P=0.089$; Figure 1 ). However, there were only a small number of deaths overall in each group.

Outcomes for Dukes' B cancers. One of 51 (2.0\%) of Dukes' B interval cancers and 9 of $81(11.1 \%)$ of screen-detected cancers were diagnosed after the incident (second round) of FOB tests. When the demographics and tumour details of the Dukes' B cancer patients were reviewed, significant differences were found in the mean age at diagnosis $(t=2.29, P=0.023$, although unlikely clinically significant) and $\mathrm{T}$ stage $\left(\chi^{2}=4.959, \mathrm{df}=1, P=0.026\right)$, both of which were greater in the interval cancer group (Table 1). Gender, ASA grade, deprivation level, tumour site, management, and 30-day mortality rate were not significantly different between screen and interval cancer groups (Table 1).

The survival rates between the two groups was equivalent (logrank Mantel-Cox $\chi^{2}=0.023, \mathrm{df}=1, P=0.880$; Figure 2), although there were again only a small number of deaths in each group.

Outcomes for Dukes' C cancers. Three of 56 (5.4\%) of Dukes' C interval cancers and 10 of $89(11.2 \%)$ of screen-detected cancers were diagnosed after the incident (second round) of FOB tests. Within the screen-detected cancer group, there were significantly more men $\left(\chi^{2}=5.486, \mathrm{df}=1, P=0.019\right)$ and left-sided tumours $\left(\chi^{2}=4.723, \mathrm{df}=1, P=0.030\right.$; Table 1$)$. A greater proportion of pT4 tumours were seen in the interval cancer group $(37.5 \%$ vs $22.5 \%$ ), although this and the overall T-stage proportions were not significantly different between groups. There were no differences found in the ASA grade, deprivation level, modality of surgery, or 30-day mortality between groups.

Patients with Dukes' C screen-detected cancers had improved survival compared to interval cancers (log-rank Mantel-Cox $\chi^{2}=6.048, \mathrm{df}=1, P=0.014$; Figure 3 ). 
Table 1. Patient demographics, tumour details, management and outcome of screen, and interval cancers by Dukes' stage

\begin{tabular}{|c|c|c|c|c|c|c|c|c|}
\hline & \multicolumn{2}{|c|}{ Dukes' stage A } & \multicolumn{2}{|c|}{ Dukes' stage B } & \multicolumn{2}{|c|}{ Dukes' stage C } & \multicolumn{2}{|c|}{ Dukes' stage D } \\
\hline & $\begin{array}{l}\text { Screen, } \\
n=125\end{array}$ & $\begin{array}{c}\text { Interval, } \\
n=36\end{array}$ & $\begin{array}{c}\text { Screen, } \\
n=81\end{array}$ & $\begin{array}{c}\text { Interval, } \\
n=51\end{array}$ & $\begin{array}{c}\text { Screen, } \\
n=89\end{array}$ & $\begin{array}{c}\text { Interval, } \\
n=56\end{array}$ & $\begin{array}{c}\text { Screen, } \\
n=21\end{array}$ & $\begin{array}{c}\text { Interval, } \\
n=44\end{array}$ \\
\hline Mean age, years (s.e.m.) & $64.75(0.28)$ & $65.80(0.46)$ & $64.88(0.35)$ & $65.99(0.39)$ & $65.49(0.32)$ & $65.77(0.38)$ & $64.05(0.71)$ & $65.24(0.45)$ \\
\hline \multicolumn{9}{|l|}{ Gender } \\
\hline Male & $87(69.6 \%)$ & $20(55.6 \%)$ & $63(77.8 \%)$ & $34(66.7 \%)$ & $66(74.2 \%)$ & $31(55.4 \%)$ & $15(71.4 \%)$ & $29(65.9 \%)$ \\
\hline Female & 38 (30.4\%) & $16(44.4 \%)$ & $18(22.2 \%)$ & $17(33.3 \%)$ & $23(25.8 \%)$ & 25 (44.6\%) & $6(28.6 \%)$ & $15(34.1 \%)$ \\
\hline \multicolumn{9}{|l|}{ ASA grade } \\
\hline $1-2$ & $70(77.8 \%)$ & $19(73.1 \%)$ & $51(77.3 \%)$ & $37(78.7 \%)$ & $65(85.5 \%)$ & $35(77.8 \%)$ & $9(75.0 \%)$ & $9(52.9 \%)$ \\
\hline $3-5$ & $20(22.2 \%)$ & 7 (26.9\%) & $15(22.7 \%)$ & $10(21.3 \%)$ & $11(14.5 \%)$ & $10(22.2 \%)$ & $3(25.0 \%)$ & $8(47.1 \%)$ \\
\hline \multicolumn{9}{|c|}{ Index of multiple deprivation quintile category } \\
\hline Most affluent & $16(12.8 \%)$ & $10(27.8 \%)$ & $4(4.9 \%)$ & $8(15.7 \%)$ & $11(12.4 \%)$ & $9(16.1 \%)$ & $0(0.0 \%)$ & $3(6.8 \%)$ \\
\hline 2 & 25 (20.0\%) & $3(8.3 \%)$ & $14(17.3 \%)$ & $6(11.8 \%)$ & $17(19.1 \%)$ & $11(19.6 \%)$ & $5(23.8 \%)$ & $5(11.4 \%)$ \\
\hline 3 & $27(21.6 \%)$ & $9(25.0 \%)$ & $20(24.7 \%)$ & 15 (29.4\%) & $19(21.3 \%)$ & $15(26.8 \%)$ & $3(14.3 \%)$ & $13(29.5 \%)$ \\
\hline 4 & $24(19.2 \%)$ & $6(16.7 \%)$ & $20(24.7 \%)$ & 10 (19.6\%) & $21(23.6 \%)$ & $12(21.4 \%)$ & $10(47.6 \%)$ & 7 (15.9\%) \\
\hline Most deprived & $33(26.4 \%)$ & $8(22.2 \%)$ & $23(28.4 \%)$ & $12(23.5 \%)$ & $21(23.6 \%)$ & 9 (16.1\%) & $3(14.3 \%)$ & $16(36.4 \%)$ \\
\hline \multicolumn{9}{|l|}{ Tumour location } \\
\hline Distal to splenic flexure & $108(86.4 \%)$ & $30(83.3 \%)$ & $54(66.7 \%)$ & $29(56.9 \%)$ & $69(77.5 \%)$ & $34(60.7 \%)$ & $16(76.2 \%)$ & $30(68.2 \%)$ \\
\hline Splenic flexure and proximal & $17(13.6 \%)$ & $6(16.7 \%)$ & $27(33.3 \%)$ & $22(43.1 \%)$ & $20(22.5 \%)$ & 22 (39.3\%) & 5 (23.8\%) & $14(31.8 \%)$ \\
\hline \multicolumn{9}{|l|}{ T stage } \\
\hline pT1 & $86(68.8 \%)$ & $22(61.1 \%)$ & & & $6(6.7 \%)$ & $3(5.4 \%)$ & $0(0.0 \%)$ & $0(0.0 \%)$ \\
\hline pT2 & 39 (31.2\%) & $14(38.9 \%)$ & & & $11(12.4 \%)$ & $4(7.1 \%)$ & $1(8.3 \%)$ & $0(0.0 \%)$ \\
\hline рT3 & & & 70 (86.4\%) & $36(70.6 \%)$ & $51(57.3 \%)$ & $28(50.0 \%)$ & $5(41.7 \%)$ & $4(40.0 \%)$ \\
\hline pT4 & & & $11(13.6 \%)$ & 15 (29.4\%) & $20(22.5 \%)$ & $21(37.5 \%)$ & $6(50.0 \%)$ & $6(60.0 \%)$ \\
\hline pTx & & & & & $1(1.1 \%)$ & $0(0.0 \%)$ & $0(0.0 \%)$ & $0(0.0 \%)$ \\
\hline \multicolumn{9}{|l|}{ Type of procedure } \\
\hline Resective & $87(69.6 \%)$ & 32 (88.9\%) & $81(100.0 \%)$ & $51(100.0 \%)$ & 89 (100.0\%) & $56(100.0 \%)$ & $12(57.1 \%)$ & $10(22.7 \%)$ \\
\hline Local excision & 38 (30.4\%) & $4(11.1 \%)$ & $0(0.0 \%)$ & $0(0.0 \%)$ & $0(0.0 \%)$ & $0(0.0 \%)$ & $0(0.0 \%)$ & 0 (0.0\%) \\
\hline Palliative & 0 (0.0\%) & $0(0.0 \%)$ & $0(0.0 \%)$ & $0(0.0 \%)$ & $0(0.0 \%)$ & $0(0.0 \%)$ & 3 (14.3\%) & 8 (18.2\%) \\
\hline No procedure & $0(0.0 \%)$ & $0(0.0 \%)$ & $0(0.0 \%)$ & $0(0.0 \%)$ & $0(0.0 \%)$ & $0(0.0 \%)$ & $6(28.6 \%)$ & $26(59.1 \%)$ \\
\hline \multicolumn{9}{|l|}{ 30-Day mortality } \\
\hline Yes & $0(0.0 \%)$ & 0 (0.0\%) & 0 (0.0\%) & $0(0.0 \%)$ & $1(1.1 \%)$ & $1(1.8 \%)$ & $0(0.0 \%)$ & $5(11.4 \%)$ \\
\hline No & $125(100.0 \%)$ & $36(100.0 \%)$ & 81 (100.0\%) & $51(100.0 \%)$ & 88 (98.9\%) & 55 (98.2\%) & $21(100.0 \%)$ & $39(88.6 \%)$ \\
\hline
\end{tabular}

When the proportions of $\mathrm{C} 1$ and $\mathrm{C} 2$ cancers between groups were reviewed (screen-detected C1 89.9\% vs interval C1 87.5\%), there were no significant differences found $\left(\chi^{2}=0.2, \mathrm{df}=1\right.$, $P=0.66)$. For Dukes' C2 cancers and combined Dukes' $\mathrm{C}$, the mean number of positive lymph nodes was significantly higher in the interval cancer group compared to the screen-detected group, as shown in Table 2.

When the survival curves were separated into Dukes' $\mathrm{C} 1$ and $\mathrm{C} 2$ CRCs, tumour site, and gender, only screen-detected cancers of Dukes' C2 stage had a significantly superior survival curve compared with the equivalent interval cancer group $\left(\chi^{2}=9.449\right.$, $\mathrm{df}=1, P=0.002)$.

Outcomes for Dukes' D cancers. Two of $22(4.5 \%)$ of Dukes' D interval cancers and 3 of $21(14.3 \%)$ of screen-detected cancers were diagnosed after the incident (second round) of FOB tests. There were no differences in gender, ASA grade, tumour location, or $\mathrm{T}$ stage observed between groups. There were significant differences in deprivation level $\left(\chi^{2}=12.044, \mathrm{df}=4, P=0.017\right)$ and rates of resective surgery (screen-detected $57.1 \%$ vs interval $22.7 \%$, $\chi^{2}=7.792, \mathrm{df}=2, P=0.020$ ) between groups. Although $11.4 \%$ of patients with an interval CRC died within the first 30 days post diagnosis compared with none of the patients with a screendetected CRC, this was not statistically significant.

Survival for these groups was found to be significantly different, with screen-detected cancers having a better survival rate (log-rank Mantel-Cox $\left.\chi^{2}=8.322, \mathrm{df}=1, P=0.04\right)$, as shown in Figure 4.
Multivariate analysis across Dukes' stages. Table 3 shows the results of the Cox proportional hazards regression analysis of variables influencing survival of patients. Dukes' stage, tumour location (HR 1.84, 95\% CI 1.19-2.83, $P=0.006$ for proximal location) and diagnostic group (HR 0.45, 95\% CI 0.29-0.69, $P<0.001$ for screen-detected CRCs) were all found to have a significant impact on the survival of patients.

\section{DISCUSSION}

This study reports a significant difference in survival between screen-detected and interval cancer patients with Dukes' C- and D-stage CRCs. Previous research has suggested that the earlier stage of screen-detected tumours is the explanation for the survival advantage over interval cancers, but this study questions whether this is the sole factor (Steele et al, 2011; Gill et al, 2012; Morris et al, $2012 \mathrm{~b}$ ). Of note, when compensating for stage of tumour on multivariate analysis, there is still a large influence from the diagnostic category, suggesting histological heterogeneity.

One compelling argument for the effects seen is that the results are solely due to lead-time bias. In other words, that both cohorts would have had the same survival outcome had they had been diagnosed through symptomatic services. However, it is equally plausible that there are biological differences between screendetected and interval cancers that make some tumours bleed more readily and therefore be more likely to be detected by a FOBt. 


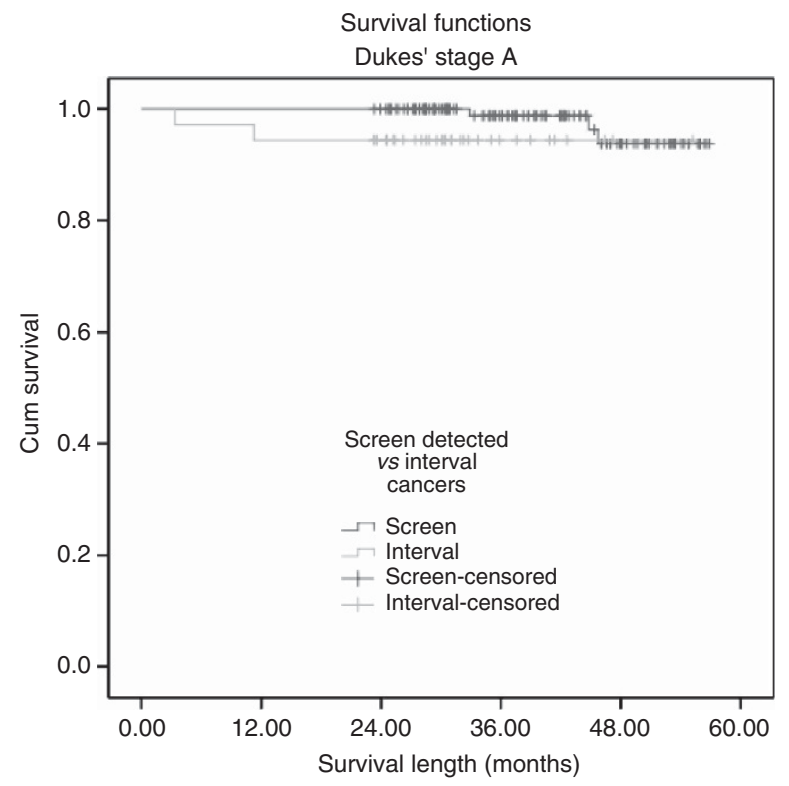

\begin{tabular}{|c|c|c|c|c|c|c|}
\hline \multicolumn{2}{|c|}{} & \multicolumn{6}{|c|}{ Time (months) } \\
\cline { 3 - 7 } \multicolumn{2}{|c|}{ Interval } & 0 & 12 & 24 & 36 & 48 \\
\cline { 2 - 7 } & Number of deaths & & 2 & 0 & 0 & 0 \\
\hline & Number at risk & 36 & 34 & 31 & 8 & 1 \\
\hline \multirow{2}{*}{ Screen } & Number of deaths & & 0 & 1 & 2 & 0 \\
\cline { 2 - 8 } & Number at risk & 125 & 125 & 123 & 72 & 30 \\
\hline
\end{tabular}

Figure 1. Survival curve for screen-detected and interval cancers of Dukes' A stage.

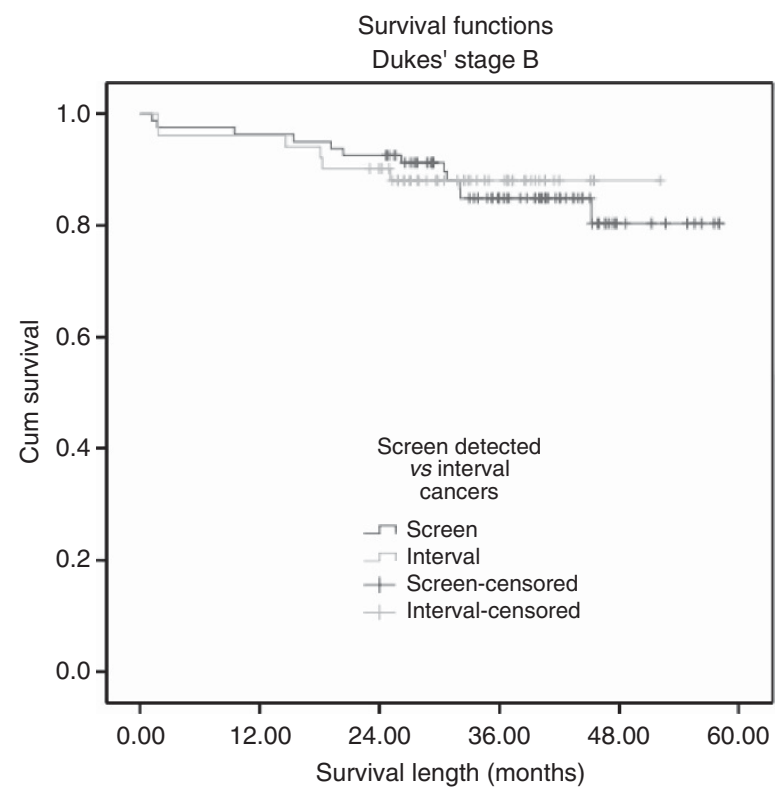

\begin{tabular}{|c|c|c|c|c|c|c|}
\hline \multicolumn{2}{|c|}{} & \multicolumn{5}{|c|}{ Time (months) } \\
\cline { 3 - 8 } \multicolumn{2}{|c|}{ Interval } & 0 & 12 & 24 & 36 & 48 \\
\cline { 2 - 8 } & Number of deaths & & 2 & 3 & 1 & 0 \\
\hline \multirow{2}{*}{ Screen } & Number at risk & 51 & 49 & 44 & 18 & 1 \\
\cline { 2 - 8 } & Number of deaths & & 3 & 3 & 5 & 1 \\
\hline
\end{tabular}

Figure 2. Survival curve for screen-detected and interval cancers of Dukes' B stage.

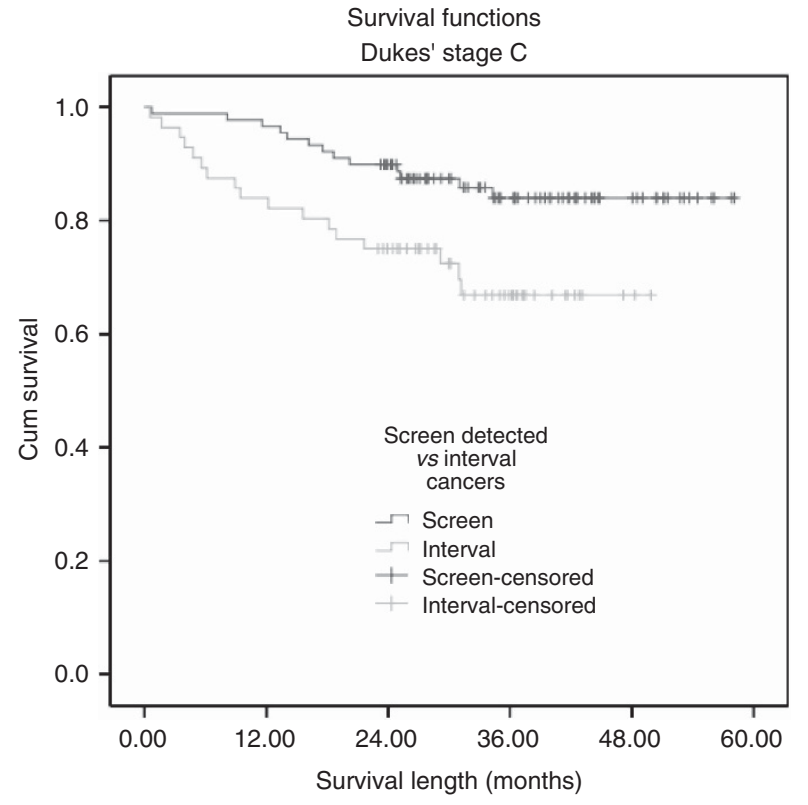

\begin{tabular}{|c|c|c|c|c|c|c|}
\hline \multicolumn{2}{|c|}{} & \multicolumn{5}{|c|}{ Time (months) } \\
\cline { 3 - 7 } \multicolumn{2}{|c|}{ Interval } & 0 & 12 & 24 & 36 & 48 \\
\cline { 2 - 7 } & Number of deaths & & 9 & 5 & 3 & 0 \\
\hline \multirow{2}{*}{ Screen } & Number at risk & 56 & 47 & 39 & 17 & 2 \\
\cline { 2 - 7 } & Number of deaths & & 3 & 6 & 4 & 0 \\
\hline
\end{tabular}

Figure 3. Survival curve for screen-detected and interval cancers of Dukes' $C$ stage.

Reasons for differences in bleeding tendency have been postulated to be related to the extent of microerosion and a thin surface epithelium of lesions in relation to their surface area (Uno and Munakata, 1995), the location and overall size of the lesions (Foutch et al, 1988) and, the degree of invasion through the submucosa of malignant cells (Hirano et al, 1996). The FOB test has also previously been shown to have differential detection rates depending on location (but not stage) of cancer, as well as a dietary influence (Macrae and John, 1982; Thomas et al, 1989). Unfortunately, data relating to size and microscopic appearance are not routinely collected by either the BCSP or NORCCAG databases.

The timing of the FOBt is at a fixed point in relation to the age of the screenee, but uptake of the test may be influenced if they are experiencing lower GI symptoms, such as bleeding. Such symptoms have been found to be prevalent among those undergoing a screening colonoscopy (Rajasekhar et al, 2012).

For Dukes' C CRCs, no differences were found in the variables known to influence outcome such as patient comorbidity (using ASA grade as a surrogate), and deprivation level. All patients were engaged in the screening programme, potentially eliminating any difference in motivation or health behaviours. However, there was a difference between male and female proportions, with a greater proportion of men having a screen-detected cancer. The improved survival curve of screen-detected cancers is therefore contrary to the improved survival of women when adjusted for stage (Aravani et al, 2009).

There are several possibilities in explaining the survival difference observed for Dukes' C CRCs. First, it may be due to the difference in tumour location. There have been three recent reports that have suggested that for left-sided colonic lesions, survival is better for stage 3 cancer (American Joint Commission on Cancer stage, with nodal involvement and worse for stage 2; 
Table 2. Mean number of positive lymph nodes and total nodes harvested for each Dukes' C stage

\begin{tabular}{|c|c|c|c|c|c|c|}
\hline \multirow[b]{2}{*}{ Dukes' Stage } & \multirow[b]{2}{*}{ Mean lymph nodes (s.e.m.) } & \multirow[b]{2}{*}{$\begin{array}{c}\text { Screen } \\
n=80\end{array}$} & \multicolumn{4}{|c|}{$\begin{array}{l}95 \% \text { Confidence interval of } \\
\text { the difference }\end{array}$} \\
\hline & & & $\begin{array}{c}\text { Interval } \\
n=49\end{array}$ & Lower & Upper & $t$-Test, $P$-value \\
\hline \multirow[t]{3}{*}{ C1 } & Positive lymph nodes & $2.9(0.3)$ & $3.6(0.6)$ & -0.63 & 2.05 & 0.293 \\
\hline & Total lymph nodes & $15.3(0.8)$ & $16.5(1.2)$ & -1.61 & 4.14 & 0.383 \\
\hline & $n=9$ & $n=7$ & & & & \\
\hline \multirow[t]{3}{*}{ C2 } & Positive lymph nodes & $3.9(0.9)$ & $14.6(4.3)$ & 2.25 & 19.12 & 0.017 \\
\hline & Total lymph nodes & $13.0(1.6)$ & $20.3(5.1)$ & -3.02 & 17.6 & 0.152 \\
\hline & $n=89$ & $n=56$ & & & & \\
\hline \multirow[t]{2}{*}{ C combined } & Positive lymph nodes & $3.0(0.3)$ & $5.0(0.9)$ & 0.43 & 3.53 & 0.013 \\
\hline & Total lymph nodes & $15.0(0.7)$ & $17.0(1.3)$ & -0.86 & 4.80 & 0.171 \\
\hline
\end{tabular}

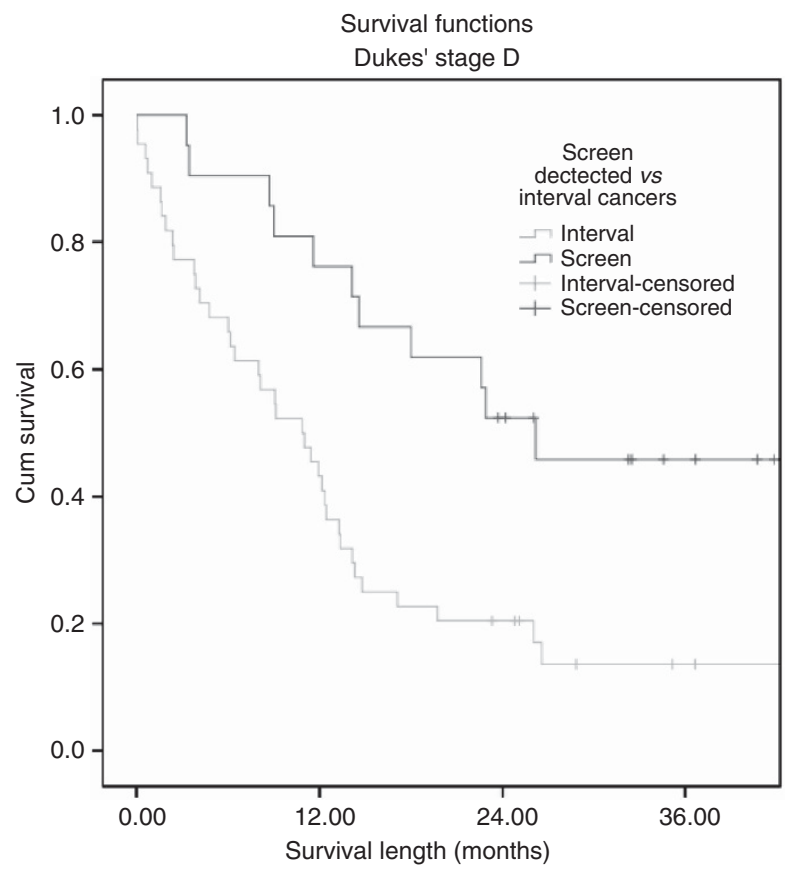

\begin{tabular}{|c|c|c|c|c|c|c|}
\hline & \multicolumn{5}{|c|}{ Time (months) } \\
\hline & & 0 & 12 & 24 & 36 & 48 \\
\hline \multirow{2}{*}{ Interval } & Number of deaths & & 25 & 10 & 2 & 0 \\
\hline & Number at risk & 44 & 19 & 8 & 2 & 0 \\
\hline \multirow{2}{*}{ Screen } & Number of deaths & & 5 & 5 & 1 & 1 \\
\hline & Number at risk & 21 & 16 & 10 & 4 & 0 \\
\hline
\end{tabular}

Figure 4. Survival curve for screen-detected and interval cancers of Dukes' D stage.

Meguid et al, 2008; Benedix et al, 2010; Weiss et al, 2011). As there was a significantly greater proportion of left-sided cancers within the screen-detected cancer group ( $78 \%$ vs $61 \%, P=0.03)$, this may explain the superior survival curve. Further evidence to support this is that survival curves analysed by tumour site (for Dukes' C cancers) are not significantly different (right-sided $P=0.097$, leftsided $P=0.184$ ).

Both groups had a similar mix of $\mathrm{C} 1$ and $\mathrm{C} 2$ stages but there was only a significant difference in survival for $\mathrm{C} 2$ tumours $(P=0.002)$. In the interval cancer group, for Dukes' C2 cancers, there was a significantly greater mean number of positive lymph nodes found (15 vs 4). An explanation for this may be that this subgroup of interval cancers was more aggressive in its regional lymph node spread, which is in turn consistent with the poorer outcomes for this group. This group may also have contained
Table 3. Cox regression multivariate analysis of variables affecting survival

\begin{tabular}{|c|c|c|c|c|}
\hline & \multicolumn{4}{|c|}{$\begin{array}{l}\text { 95\% Confidence } \\
\text { interval }\end{array}$} \\
\hline Variables & $\begin{array}{c}\text { Hazard } \\
\text { ratio }\end{array}$ & Lower & Upper & $\begin{array}{c}\text { Significance } \\
\text { (P-value) }\end{array}$ \\
\hline Age (per year) & 1.01 & 0.95 & 1.08 & 0.730 \\
\hline \multicolumn{5}{|l|}{ Sex } \\
\hline Female & 1.00 & & & \\
\hline Male & 0.95 & 0.63 & 1.43 & 0.806 \\
\hline \multicolumn{5}{|l|}{ Diagnostic category } \\
\hline Interval & 1.00 & & & \\
\hline Screen-detected & 0.45 & 0.29 & 0.69 & $<0.001$ \\
\hline \multicolumn{5}{|c|}{ Index of multiple deprivation quintile category } \\
\hline Most affluent & 1.00 & & & \\
\hline 2 & 0.75 & 0.29 & 1.92 & 0.549 \\
\hline 3 & 1.02 & 0.44 & 2.34 & 0.962 \\
\hline 4 & 1.78 & 0.79 & 4.02 & 0.168 \\
\hline Most deprived & 2.01 & 0.92 & 4.40 & 0.079 \\
\hline \multicolumn{5}{|l|}{ ASA grade } \\
\hline ASA 1-2 & 1.00 & & & \\
\hline ASA 3-5 & 1.56 & 0.90 & 2.72 & 0.114 \\
\hline \multicolumn{5}{|l|}{ Tumour site } \\
\hline Distal to splenic flexure & 1.00 & & & \\
\hline Splenic flexure and proximal & 1.84 & 1.19 & 2.83 & 0.006 \\
\hline \multicolumn{5}{|l|}{ Dukes' stage } \\
\hline Dukes' A & 1.00 & & & \\
\hline Dukes' B & 3.85 & 1.41 & 10.54 & 0.009 \\
\hline Dukes' $^{\prime} \mathrm{C}$ & 6.51 & 2.49 & 16.97 & $<0.001$ \\
\hline Dukes' D & 35.30 & 13.57 & 91.87 & $<0.001$ \\
\hline
\end{tabular}

tumours that were associated with adverse histological features such as extramural lymphovascular invasion, tumour-associated lymphocytes, or peritoneal involvement which the NORCCAG database does not contain data upon (Shepherd et al, 1997; Mitchard et al, 2010). Alternatively, lead-time bias would have allowed more time for metastases for this subgroup to become apparent.

An alternative explanation for differences in outcomes for each stage of tumour, between interval and screen-detected groups is that, instead of interval cancer group being more aggressive, screen-detected cancers are more indolent than cancers detected symptomatically pre-screening. Interval CRCs might be expected to have a worse survival rate compared to a control group. However, as previously reported, the survival curves for interval cancers and control group cancers (non-screened population) are equivalent (Gill et al, 2012). Therefore, the improved survival in 
the screen-detected group could be secondary to these tumours having a low potential for metastasis, and hence reducing the risk of a patient having micro-metastases or circulating tumour cells remaining in situ after initial cancer treatment.

Limitations of this research are in the subgroup analysis of $\mathrm{C} 1$ and C2 CRC groups, where small numbers make it difficult to draw any firm conclusions. The NORCCAG database does not contain data on the management of metastases of patients that present with Dukes' D cancer. It is therefore not known whether there was a difference in resection rate for metastases between the two groups. If there was a higher rate of resection in the screen-detected group this might, at least partially, explain the survival advantage. Data regarding prior endoscopic treatment outwith the screening programme were not available. Although, it is likely that all study patients have had no previous endoscopic experience, as those who are enrolled on a surveillance programme are asked to discuss this with the programme (NHS Cancer Screening Programmes, 2006).

It is unknown whether the above results will be reproduced with the introduction of endoscopic screening, such as flexible sigmoidoscopy screening in the UK. However, a US study has shown similar findings with improved survival rates for patients detected through screening colonoscopy (Amri et al, 2013). The implications of a biological difference in screen-detected cancers may influence future screening strategies that are based upon a tumour's propensity to bleed, against those that endoscopically screen a population.

The relationship between lead-time bias $v s$ a difference in the biology of screen-detected and interval CRCs and the outcome of patients remains unknown, therefore a further detailed analysis of the biology of screen and post FOBt interval cancers is planned. This will help to answer questions regarding the nature and structure of these cancers, both on a macroscopic and microscopic level.

\section{AUTHOR CONTRIBUTIONS}

MDG collected and analysed the data, and wrote the manuscript. All other authors contributed to the design of the study, and review of the paper. All authors have approved the final version of the manuscript.

\section{REFERENCES}

Amri R, Bordeianou LG, Sylla P, Berger DL (2013) Impact of screening colonoscopy on outcomes in colon cancer surgery. JAMA Surg 148(8): 747-754.

Arain MA, Sawhney M, Sheikh S, Anway R, Thyagarajan B, Bond JH, Shaukat A (2010) CIMP status of interval colon cancers: another piece to the puzzle. Am J Gastroenterol 105(5): 1189-1195.

Aravani A, Thomas J, Day M, Forman D, Morris E, Tatarek-Gintowt R (2009) Survival by Stage of Colorectal Cancer in England: Northern and Yorkshire Cancer Registry and Information Service.

Benedix F, Kube R, Meyer F, Schmidt U, Gastinger I, Lippert H. Group tCRCS (2010) Comparison of 17,641 patients with right- and left-sided colon cancer: differences in epidemiology, perioperative course, histology, and survival. Dis Colon Rectum 53(1): 57-64. doi:10.1007/DCR.0b013e3181c703a4.

Cancer Research UK (2010) Bowel (colorectal) cancer - UK incidence statistics.

Cooper GS, Xu F, Barnholtz Sloan JS, Schluchter MD, Koroukian SM (2012) Prevalence and predictors of interval colorectal cancers in Medicare beneficiaries. Cancer 118(12): 3044-3052.
Foutch P, Manne R, Sanowski R, Gaines J (1988) risk factors for blood loss from adenomatous polyps of the large bowel: a colonoscopic evaluation with histological correlation. J Clin Gastroenterol 10(1): 50-56.

Gill MD, Bramble MG, Rees CJ, Lee TJW, Bradburn DM, Mills SJ (2012) Comparison of screen-detected and interval colorectal cancers in the Bowel Cancer Screening Programme. Br J Cancer 107(3): $417-421$.

Harvey NT, Ruszkiewicz A (2007) Serrated neoplasia of the colorectum. World J Gastroenterol 13(28): 3792-3798.

Hirano K, Uno Y, Munakata A, Yoshida Y (1996) Factors that influence bleeding in superficial-type colorectal tumours: study of endoscopic and histological correlates. J Gastroenterol 31: 518-524.

Macrae FA, John DJS (1982) Relationship between patterns of bleeding and Hemoccult sensitivity in patients with colorectal cancers or adenomas. Gastroenterology 82(5): 891-898.

Meguid RA, Slidell MB, Wolfgang CL, Chang DC, Ahuja N (2008) is there a difference in survival between right- versus left-sided colon cancers? Ann Surg Oncol 15(9): 2388-2394.

Mitchard JR, Love SB, Baxter KJ, Shepherd NA (2010) How important is peritoneal involvement in rectal cancer? A prospective study of 331 cases. Histopathology 57: 671-679.

Morris EJA, Whitehouse LE, Farrell T, Nickerson C, Thomas JD, Quirke P, Rutter MD, Rees C, Finan PJ, Wilkinson JR, Patnick J (2012a) A retrospective observational study examining the characteristics and outcomes of tumours diagnosed within and without of the English NHS Bowel Cancer Screening Programme. Br J Cancer 107: 757-764.

Morris EJA, Whitehouse LE, Farrell T, Nickerson C, Thomas JD, Quirke P, Rutter MD, Rees C, Finan PJ, Wilkinson JR, Patnick J (2012b) A retrospective observational study examining the characteristics and outcomes of tumours diagnosed within and without of the English NHS Bowel Cancer Screening Programme. Br J Cancer 107(5): 757-764.

NHS Cancer Screening Programmes (2006) Guide Book for Programme Hubs and Screening Centres: NHS Bowel Cancer Screening Programme.

Rajasekhar PT, Ritchie M, Rutter MD, Clifford G, Waddup G, Dempsey N, Rubin GP, Rees CJ (2012) Lower gastrointestinal symptoms are prevalent among individuals colonoscoped within the Bowel Cancer Screening Programme. Colorectal Dis 14(9): e603-e607.

Sawhney M, Farrar W, Gudiseva S, Nelson D, Lederle F, Rector T, Bond J (2006) Microsatellite instability in interval colon cancers. Gastroenterology 131(6): 1700-1705.

Shaukat A, Arain M, Thaygarajan B, Bond JH, Sawhney M (2010) Is BRAF mutation associated with interval colorectal cancers? Dig Dis Sci 55(8): 2352-2356.

Shepherd NA, Baxter KJ, Love SB (1997) The prognostic importance of peritoneal involvement in colonic cancer: a prospective evaluation. Gastroenterology 112: 1096-1102.

Steele RJC, McClements P, Watling C, Libby G, Weller D, Brewster DH, Black R, Carey FA, Fraser CG (2011) Interval cancers in a FOBT-based colorectal cancer population screening programme: implications for stage, gender and tumour site. Gut 61: 576-581.

Thomas WM, Pye G, Hardcastle JD, Chamberlain J, Charnley RM (1989) Role of dietary restriction in Haemoccult screening for colorectal cancer. Br J Surg 76(9): 976-978.

Uno Y, Munakata A (1995) Endoscopic and histologic correlates of colorectal polyp bleeding. Gastrointest Endosc 41(5): 460-467.

Weiss JM, Pfau PR, O'Connor ES, King J, LoConte N, Kennedy G, Smith MA (2011) Mortality by stage for right- versus left-sided colon cancer: analysis of surveillance, epidemiology, and end results-Medicare Data. J Clin Oncol 29(33): 4401-4409.

This work is published under the standard license to publish agreement. After 12 months the work will become freely available and the license terms will switch to a Creative Commons AttributionNonCommercial-Share Alike 3.0 Unported License. 